\title{
THE EFFICIENCY OF HIGHER EDUCATION INSTITUTIONS IN ENGLAND REVISITED: COMPARING ALTERNATIVE MEASURES
}

\author{
Geraint Johnes \\ Lancaster University Management School \\ Lancaster LA1 4YX \\ United Kingdom \\ T: +44 1524594215 \\ F: +44 1524594244 \\ E: G.Johnes@lancaster.ac.uk \\ Kaoru Tone \\ National Graduate Institute for Policy Studies \\ 7-22-1 Roppongi, Minato-ku, Tokyo 106-8677 \\ Japan \\ T: +81364396000 \\ F: +81364396010 \\ E: tone@grips.ac.jp
}

May 2016

\section{ABSTRACT}

Data envelopment analysis has often been used to evaluate efficiency in the context of higher education institutions. Yet there are numerous alternative non-parametric measures of efficiency available. This paper compares efficiency scores obtained for institutions of higher education in England, 2013-14, using three different methods: the original Charnes et al. (1978) method and two slacks-based methods (SBM-Min and SBM-Max) developed by Tone $(2001,2015)$. The findings suggest that results are highly sensitive to methodology chosen. Hence caution is required in applying the results in any policy context.

JEL Classification: D24, 121, 123

Keywords: $\quad$ higher education; efficiency

The authors gratefully acknowledge, without implication, the extremely useful comments made by three referees of this journal. 


\section{Introduction}

Data envelopment analysis (DEA) has developed into a widely used tool for examining the efficiency of decision making units, particularly in contexts where multiple inputs are used to produce multiple outputs, and where market prices that might be used as weights on these inputs and outputs are not readily observed. By comparing the efficiency of units against one another, units that represent best practice can be identified. This information is commonly used in benchmarking exercises, where peer groups of efficient performers are employed as exemplars for other producers.

There are, however, numerous ways in which efficiency can be measured. Most obviously, different exercises might involve the use of different combinations of inputs and outputs, and hence yield different results. Differences can also exist in the methods of analysis used in studies. Sometimes these differences are quite subtle, yet they can, in principle at least, lead to startlingly different results. There are reasons therefore to believe that the choice of method matters. Yet our understanding of how important this can be is limited by a paucity of studies that compare the results of applying different methods to empirical data drawn from the world. The aim of the present paper is to investigate how sensitive to choice of method the results of a DEA-type efficiency analysis can be, taking as context higher education institutions in England. These have been extensively studied in the past using DEA methods, and so form an appropriate laboratory for analysis.

The remainder of the paper is structured as follows. Section 2 provides a brief review of the literature on DEA in the study of education. Section 3 focuses on the methodological approaches, and the following section presents and compares the results obtained using each method. The paper ends, in Section 5, with a conclusion.

\section{Literature}

The pioneering work of Farrell (1957) has led to a considerable literature on efficiency evaluation. Building on this work, DEA, a non-parametric method based on linear programming, was introduced by Charnes et al. (1978). Their model and variants thereof have come to be very commonly applied in the literature.

The model is particularly useful in contexts where a multiplicity of inputs is used to produce a multiplicity of outputs, and where market prices (which in other circumstances can be used to weight the inputs and outputs, thereby enabling a straightforward comparison of weighted input and weighted output) are absent. This is often the case for publicly provided goods and services. Consequently the use of DEA has been particularly common in areas such as health and education.

DEA finesses the problem of absent prices by selecting for each decision making unit the vector of input and output weights that maximises the ratio of its weighted output to weighted input, subject to the constraint that no other decision making unit would, were these weights applied across the board, score above $100 \%$ efficiency. Each decision making unit thus has its own set of weights; since these weights typically differ across decision making units, they are not parameters. This approach has merits and demerits; a notable 
advantage is that it allows comparison of decision making units that differ in terms of their priorities or 'missions'.

An early analysis of the efficiency of UK universities is provided by Athanassopoulos and Shale (1997). Using data from the early '90s for the 'old' universities (that had university status prior to 1992 and that have both a teaching and research mission), they find high levels of technical efficiency in a model where inputs include student and staff numbers, quality of the student intake and financial variables and where outputs include numbers of completing students and research rating. The average efficiency score in this model is a little over $97 \%$, and the minimum score is over $77 \%$. Scores are somewhat lower (on average around $86 \%$ ) in a model where only financial inputs are included.

Johnes (2006) extends this analysis to examine data for over 100 universities - including those institutions given university status in 1992. This analysis confirms a high average level of efficiency. While no systematic differences in efficiency can be observed across groups of institutions (for example, those with university status before and after 1992), bootstrapping confirms that the efficiency scores of institutions at the bottom end of the distribution are significantly lower than is the case for those at the top. Bootstrapping efficiency scores involves running numerous repeated DEA exercises on a sample (with replacement) of the decision-making units in order to build up a distribution of efficiency scores for each unit from which a confidence interval can be constructed (Simar and Wilson, 1998). In subsequent analysis, Johnes (2008) addresses the change in efficiency over time. She finds that the frontier has shifted outwards, indicating improvement in best practice, but that the average efficiency of institutions that fall short of the frontier has declined in relation to that best practice.

Agasisti and Johnes (2009), building on comparative work undertaken by Joumady and Ris (2005), confirm many of the above findings. They compare the efficiency of universities in England and Italy. They find that the English institutions generally have higher technical efficiency scores than their Italian counterparts (on average, $81 \%$ versus $64 \%$ ). Progress over time has been slower in England, however, with Italian universities increasing their efficiency relative to English institutions over the period under study. Both the Johnes (2008) and Agasisti and Johnes (2009) studies use a fairly short timeframe, but a much longer period has been analysed by Flegg et al. (2014). This confirms the results of the earlier analyses in finding that the frontier has shifted out markedly over time, with only modest improvements in the technical efficiency of the average institution.

Many recent studies continue the trend in providing comparative analyses across a number of countries. Particularly noteworthy examples include a series of contributions based on the Aquameth (Advanced QUAntitative METHods for the Evaluation of the Performance of Public Sector Research) and EUMIDA (European MlcroData) data which gather together information on a comparable basis for higher education institutions in EU member states (Bonaccorsi et al., 2007; Daraio et al., 2014). These confirm that the variation in efficiency across institutions appears to be increasing over time. Another significant contribution is that of Wolszczak-Derlacz and Parteka (2011), who examine institutions across seven countries. They find that efficiency varies considerably across institutions, and augment their analysis with a second stage in which determinants of efficiency scores are modelled. 
Economies of scale, subject mix, funding mix and staff composition are all found to be significant sources of the variation in measured efficiency.

The workhorse analytical framework typically employed in studies such as those reviewed here is a standard DEA model. Non-parametric methods designed to evaluate efficiency come in a variety of flavours, however, and it is instructive to compare the results obtained using different techniques. That this has typically not been done in the received literature represents a deficiency of that earlier work, and this is something that we aim to remedy in the present paper. In the next section, we outline three of these models as a prelude to comparing results obtained when applying these methods to data on English institutions of higher education.

\section{Methodology}

In simple DEA models, the efficiency score of a unit is determined as a ratio of the distance from the origin of the outturn relative to the efficiency frontier. Examples of such models include the constant returns to scale model developed by Charnes et al. (1978) - hereafter CCR - and a variable returns to scale model due to Banker et al. (1984) - often labelled BCC. This distance between the outturn and frontier is measured along a ray that passes through the outturn from the origin. This ray is not, except by chance, orthogonal to the frontier. An orthogonal ray would allow the minimum distance between the outturn and the frontier to be computed. Efficiency scores calculated using the ray from the origin therefore provide downwardly biased measures of distance from the frontier.

This is illustrated in Figure 1, which provides a typical representation of the DEA problem. Point $A$ represents the decision making unit of interest. The piecewise linear frontier, BHF, indicates combinations of decision making units that are technically efficient. The line OCJG is a ray from the origin that is tangent to the frontier, and this allows evaluation of scale efficiency. Conventional DEA models such as BCC allow computation of efficiency on an output orientation - so that technical efficiency can be measured by the ratio EA/EF and scale efficiency by $E F / E G$ - or on an input orientation - where the corresponding measures are respectively $D B / D A$ and $D C / D B$. In general these measures are different from one another; orientation matters. But neither input nor output orientation involves a comparison of point A with the nearest point on either the technical efficiency frontier, BHF, or the line representing scale efficiency, OCJG. The points along these frontiers that should be of interest in this context are $\mathrm{H}$ and $\mathrm{J}$ respectively.

Alternative computations of efficiency scores, notably slacks based measures (SBM), are well suited to deriving indicators that are not based on either input or output orientation, but that instead allow comparison of $\mathrm{A}$ with $\mathrm{H}$ (for evaluating technical efficiency) or $\mathrm{J}$ (for evaluating scale efficiency). Indeed, where $\mathrm{H}$ and $\mathrm{J}$ are orthogonal to the frontier, these represent the closest points of the frontier to the outturn. Recent work by Tone $(2001,2015)$ develops a family of such models. We focus here on two, namely SBM-Min and SBM-Max. A solution method for the first of these problems has been available for some time; it is known, however, to provide a lower bound to the efficiency score of each decision making 
unit. This being the case, it is useful to solve also the SBM-Max problem, which, by providing an upper bound, yields a useful point of comparison.

It is useful to begin the formal methodological exposition by reference to the simplest DEA model, namely CCR. This involves the $k$ th of $n$ decision making units, $j=1, \ldots, n$, in choosing weights, $u_{r}$ and $v_{i}$, on each of its $h$ outputs and $m$ inputs, so that its weighted output is maximised, subject to the constraint that, using these weights, the ratio of weighted output to weighted input can for no decision making unit exceed unity. Formally, for each decision making unit, the following must be solved

$\operatorname{Max} \sum_{r=1}^{h} u_{r} y_{r k} / \sum_{i=1}^{m} v_{i} x_{i k}$

subject to

$\sum_{r=1}^{h} u_{r} y_{r j} / \sum_{i=1}^{m} v_{i} x_{i j} \leq 1 \quad j=1, \ldots, n$

$u_{r}, v_{i}>0 \forall r, i$

This is converted into a linear program by moving the denominator of the optimand into the contraints, and is then routinely solved.

Based, as it is, on a ratio of weighted output to weighted input, the CCR model provides a radial measure of efficiency. As illustrated in Figure 1, non-radial measures may also be derived, and are in many circumstances preferable to either an output or input oriented approach. In particular, where decision making units are free to vary some inputs and outputs, but face constraints in their ability to vary others, it is appropriate to focus on the input and output specific slacks.

The second model that we consider represents an attempt to deal with these issues. It is a slacks based measure, namely SBM-Min. The measure is due to Tone (2001), though Pastor et al. (1999) independently developed a similar model. It has its roots in the Russell measure developed by Färe and Lovell (1978). In this model, the $k$ th decision making unit is described by input and output vectors such that

$x_{k}=X \lambda+s^{-}$

$\boldsymbol{y}_{k}=Y \lambda-\boldsymbol{s}^{+}$

where $X$ and $Y$ denote respectively the $(m \times n)$ order input matrix and the $(h \times n)$ order output matrix associated with the frontier, and where the $s$ terms are slacks. The slacks allow inequality constraints - indicating that the decision making unit operates within the frontier - to be expressed as equalities. Optimisation of efficiency may thus be regarded as an exercise in choosing the slacks and the weights vector, $\lambda$, to

$\operatorname{Min} \rho=\frac{1-\left(\frac{1}{m}\right) \sum_{i=1}^{m} s_{i}^{-} / x_{i k}}{1+\left(\frac{1}{h}\right) \sum_{r=1}^{h} s_{r}^{+} / y_{r k}}$ 
subject to

$$
\begin{array}{lll}
x_{i k}=\sum_{j=1}^{n} \quad x_{i j} \lambda_{j}+s_{i}^{-} & i=1, \ldots, m \\
y_{r k}=\sum_{j=1}^{n} \quad y_{r j} \lambda_{j}+s_{r}^{-} & r=1, \ldots, h \\
\lambda \geq \mathbf{0}, \boldsymbol{s}^{-} \geq 0, \boldsymbol{s}^{+} \geq 0 . &
\end{array}
$$

This is a non-linear program because the minimand contains a quotient that includes slacks in both numerator and denominator. As in the case of the CCR model, however, the denominator can be moved into the set of constraints, thereby allowing the problem to be solved as a standard linear program.

With zero values for the slacks, $\rho=1$. So the SMB-Min model identifies the same decision making units as efficient as does the CCR model. Otherwise the different specification of the optimand leads to efficiency scores on inefficient decision making units that differ across the two methods. In solving for a minimum, it should be noted that SBM-Min provides a lower bound on efficiency estimates - it compares the outturn with what is, within bounds, the furthest point on the frontier.

An alternative model, providing instead an upper bound, is due to Hadi-Vencheh et al. (2015). Their model is computationally demanding, however, but an approximator to this, relying only on linear programs, has recently been developed by Tone (2015), and is known as SBM-Max. In this approach, SBM-Min is first applied to the data to identify efficient decision making units. Suppose there are $B$ such units. For each inefficient unit, the following two programs are solved $B+1$ times, first defining $R_{k}^{*}$ as the unit's reference set of efficient peers, then as a set comprising only the efficient unit closest to the inefficient unit of interest, then as the set of the two closest efficient units, then the set of three, and so on until the set of all efficient units is considered. The first of the programs chooses slacks and weights to maximise the efficiency measure:

$\operatorname{Max} \frac{1-\left(\frac{1}{m}\right) \sum_{i=1}^{m} s_{i}^{-} / x_{i k}}{1+\left(\frac{1}{h}\right) \sum_{r=1}^{h} s_{r}^{+} / y_{r k}}$

subject to

$$
\begin{array}{lll}
x_{i k}=\sum_{j \in R_{k}^{*}} \quad x_{i j} \lambda_{j}+s_{i}^{-} & i=1, \ldots, m \\
y_{r k}=\sum_{j \in R_{k}^{*}} \quad y_{r j} \lambda_{j}+s_{r}^{-} & r=1, \ldots, h \\
\lambda \geq \mathbf{0}, \boldsymbol{s}^{-} \geq 0, \boldsymbol{s}^{+} \geq 0 . &
\end{array}
$$


and the second program, taking the optimal slacks, $\boldsymbol{s}^{-*}$ and $\boldsymbol{s}^{+*}$, obtained in the above program as given, projects the solution onto the frontier by solving

$\operatorname{Min} \frac{1-\left(\frac{1}{m}\right) \sum_{i=1}^{m} s_{i}^{-} /\left(x_{i k}-s_{i}^{-*}\right)}{1+\left(\frac{1}{h}\right) \sum_{r=1}^{h} s_{r}^{+} /\left(y_{r k}+s_{i}^{+*}\right)}$

subject to

$x_{i k}-s^{-*}=\sum_{j \in R} e \quad x_{i j}^{e} \quad \lambda_{j}+s_{i}^{-} \quad i=1, \ldots, m$

$y_{r k}+s^{+*}=\sum_{j \in R^{e}} \quad y_{r j}^{e} \quad \lambda_{j}+s_{r}^{-} \quad r=1, \ldots, h$

$\lambda \geq \mathbf{0}, \boldsymbol{s}^{-} \geq 0, \boldsymbol{s}^{+} \geq 0$.

where $x^{e}$ and $y^{e}$ respectively denote values observed in the efficient units, and $R^{e}$ denotes the set of all efficient units. Denoting the optimal slacks from this second program by $\boldsymbol{S}^{-* *}$ and $\boldsymbol{s}^{+* *}$, calculate the efficiency score associated with each of the $B+1$ solutions as

$\rho=\frac{1-\left(\frac{1}{m}\right) \sum_{i=1}^{m}\left(s_{i}^{-*}+s_{i}^{-* *}\right) / x_{i k}}{1+\left(\frac{1}{h}\right) \sum_{r=1}^{h}\left(s_{r}^{+*}+s_{r}^{+* *}\right) / y_{r k}}$

Once all $B+1$ efficiency measures, that is the $\rho$ terms, have been obtained, the largest of these is taken to be the unit's efficiency score in the SBM-Max model.

It is useful at this stage to compare the three methods outlined above. In the CCR model, the optimand is the ratio of weighted output to weighted input and this provides also the measure of efficiency. For an inefficient decision making unit, a pari passu increase in (all) outputs or decrease in (all) inputs is assumed to be needed in order to restore efficiency. In this respect, CCR is often referred to as a radial measure of efficiency. However, in real world businesses, not all inputs or outputs behave in this proportional way. For example, if we employ labour, materials and capital as inputs, some of them are substitutional and do not change proportionally. Another shortcoming of the radial models is the neglect of slacks in reporting the efficiency score. In many cases, we find that large non-radial slacks remain. If these slacks have an important role in evaluating managerial efficiency, the radial approaches may mislead the decision-maker when we utilising the efficiency score as the only index for evaluating performance of decision making units. Furthermore, the CCR model must be either input-oriented or output-oriented. It cannot deal with both input and output simultaneously. This inevitably affects comparison with non-oriented models.

By way of contrast, the slacks-based measures are non-radial, and can therefore deal with both orientations at the same time. Non-radial models put aside the assumption of proportionate changes in inputs and outputs, and deal with slacks directly. They may thus discard varying proportions of original inputs and outputs. Among the non-oriented models, 
the SBM-Min model evaluates the efficiency of decision making units referring to the furthest frontier point within a range. This results in the worst score for a unit and the projection may go to a remote point on the efficient frontier which may be inappropriate as a reference.

By way of contrast, the SBM-Max model obtains an approximation of the closest points on the efficient frontier - an approximation because it is designed to be solved with reasonable computation loads using only popular linear programming codes. We can attain an efficient status with fewer input reductions and output expansions than is the case with the SBMMin model. Thus, projection by the SBM-Max model represents a practical Kaizen (improvement) over more standard models.

The three methods may be illustrated vividly by reference to Figure 2 . A producer at point $P$ has efficiency measured by its distance from various points on the frontier $-R, Q$ and $S$ respectively for the CCR, SBM-Min and SBM-Max models.

The aim in the remainder of this paper is to compare the three measures defined above of the efficiency of higher education institutions in England - obtained by solving CCR, SBMMin and SBM-Max models. To the extent that the measures are congruent, the results will provide useful information about the institutions. However, as we shall see, there are instances where the measures provide strikingly divergent indicators, and this suggests that caution is needed in interpreting the results of any analysis of efficiency in this sector.

\section{Data and Analysis}

The data used in this section all come from the UK Higher Education Statistics Agency (HESA). Full-time equivalent (FTE) numbers of taught students and of research students come from the Mstates Record (https://www.hesa.ac.uk/dox/dataTables/ems/download/hesa_emr_1314.xlsx), and the remaining data come from the HESA publication Finances of Higher Education Providers. All data refer to the year 2013-14.

All models solved in this section have total expenditure (minus residence and catering costs) as the sole input, and three outputs, namely: taught student FTE; research student FTE; and research activity, measured by income from research grants. While different studies differ in detail on the set of inputs and outputs used, this specification of the model is consonant with much of the literature - see, for example, Thanassoulis et al. (2011). Institutions with zero values for any of these outputs are dropped from the data set. Three other institutions are also dropped because they are, in various respects, not comparable with the rest of the sector - these are the (private) University of Buckingham, the (distance-learning) Open University, and the University of London Institutes and Activities. This leaves a total of 118 English higher education institutions. Student number data for the University Campus, Suffolk, are divided between the Universities of East Anglia and Essex. Financial data for the Liverpool School of Tropical Medicine are amalgamated with those of the University of Liverpool. 
Applying three methods, CCR, SBM-Min and SBM-Max, to solve for the efficiency of these institutions yields markedly divergent results. These are summarised in Figures 3 through 5 , and descriptive statistics are given in Table 1. Full results are reported in the appendix. There are six higher education institutions with efficiency scores of 1 ; these are of course the same using any of the three methods. The efficient institutions are: Birkbeck College, Bishop Grossteste University, Huddersfield University, Imperial College, the Institute of Education and the London School of Hygiene and Tropical Medicine. Below this level of efficiency, however, the efficiency scores obtained using SBM-Min are, across the distribution, considerably lower than those that result from the other two methods. The CCR efficiency scores are somewhat lower than the SBM-Max scores (typically about $10 \%$ lower) across most of the distribution, but at the lower extreme of the distribution there are two observations where the SBM-Max scores are lower than the CCR scores.

While the CCR and SBM-Max distributions are superficially not dissimilar, there are however some substantial differences between these two methods in the efficiency scores achieved by individual institutions. Some 18 institutions achieve lower scores under SBM-Max than they do under CCR, while the reverse is true for 94 institutions. Five institutions achieve scores under SBM-Max that are at least 0.2 points higher than those achieved under CCR. Meanwhile, four institutions achieve CCR scores at least 0.2 points higher than the corresponding SBM-Max scores. With one exception, all nine of these institutions are small and/or specialist providers. The institutions with higher CCR scores are the Institute of Cancer Research, Newman University, Norwich University of the Arts, and the School of Oriental and African Studies. Those with higher SBM-Max scores are the Central School of Speech and Drama, Guildhall School of Music and Drama, the Royal College of Music, the Royal Northern College of Music, and - the only large, comprehensive institution in this group - the University of Liverpool.

To probe this a little further, the correlations (and rank correlations) between the various measures may be calculated - first for the full sample, and secondly for the sample excluding smaller institutions (those with expenditure of under $f 25 \mathrm{~m}$ over the year). These are shown in Table 2 . It is readily observed that excluding the smaller institutions has, if anything, the effect of weakening the correlations between the three measures. We are unable therefore to conclude that the weak relationship between the measures (and in particular between SBM-Min and the other measures) is due to the presence in the sample of these idiosyncratic organisations.

All three methods of analysis used here have been devised as means of evaluating efficiency. As we have seen, the results differ markedly across the three methods. This does not, however, mean that some methods are better than others at measuring efficiency rather it is the consequence of employing three (subtly) different definitions of efficiency in examining the data. End users of this type of analysis therefore need to be conscious that different measures measure differently, sometimes substantially so, and they should therefore choose which measure they wish to use in any particular context with care. 


\section{Conclusion}

The three methods considered in the present paper all constitute reasonable ways of measuring efficiency. The wide divergences in results across the methods are in line with results obtained in the health sector by Tone (2015). These findings together suggest therefore that caution should be used in interpreting the efficiency scores that are produced from any one method. In particular, the distribution of efficiencies obtained by SBM-Min differs markedly from those produced using the other methods.

Data Envelopment Analysis and related techniques are now routinely used in policy contexts. Agrell and Bogetoft (2013), for example, list several countries in which it is used to define parameters used in regulatory frameworks in the energy sector. Its use has been less widespread in the context of education, but the possibilities afforded by the method have attracted considerable interest from policy makers (see, for example, Smith and Street, 2006; Johnes and Johnes, 2013). It is therefore critical that, in advance of practical implementation, users should understand the differences in assumptions that underpin alternative methodologies and that these various approaches can lead to wide variation in results. 


\section{References}

Agasisti, T. and G. Johnes (2009) Beyond frontiers: comparing the efficiency of higher education decision making units across more than one country, Education Economics, 17, 59-79.

Agrell, P.J. and P. Bogetoft (2013) Benchmarking and regulation, CORE Discussion Paper, http://uclouvain.be/cps/ucl/doc/core/documents/coredp2013_8.pdf

Athanassopoulos, A. and E. Shale (1997) Assessing the comparative efficiency of higher education institutions in the UK by means of data envelopment analysis, Education Economics, 5, 117-134.

Banker, R., A. Charnes and W.W. Cooper (1984) Models for the estimation of technical and scale efficiencies in data envelopment analysis, Management Science, 30, 1078-1092.

Bonaccorsi, A., C. Daraio and L. Simar (2007) Efficiency and productivity in European universities: exploring trade-offs in the strategic profile, in Bonaccorsi, Andrea and Cinzia Daraio (eds) Universities and Strategic Knowledge Creation, Cheltenham: Edward Elgar.

Charnes, A., W.W. Cooper and E. Rhodes (1978) Measuring the efficiency of decision making units, European Journal of Operational Research, 2, 429-444.

Daraio, C., A. Bonaccorsi and L. Simar (2014) Rankings and university performance: a conditional multidimensional approach, http://risis.eu/wpcontent/uploads/2014/08/daraio_bonaccorsi_simar_cond_rankings_TR-n-9-2014.pdf.

Färe, R. and C.A.K. Lovell (1978) Measuring the technical efficiency of production, Journal of Economic Theory, 19, 150-162.

Farrell, M.J. (1957) The measurement of productive efficiency, Journal of the Royal Statistical Society A, 120, 253-290.

Flegg, A.T., D.O. Allen, K. Field and T.W. Thurlow (2014) Measuring the efficiency of British universities: a multi-period data envelopment analysis, Education Economics, 12, 231-249.

Hadi-Vencheh, A., J. Jablonsky and A. Esmaeilzadeh (2015) The slack based measure model based on supporting hyperplanes of production possibility set, Expert Systems with Applications, 42, 6522-6529.

Higher Education Statistics Agency (2015) Finances of Higher Education Institutions, Cheltenham: HESA.

Johnes, G. and J. Johnes (2013) Efficiency in the higher education sector: a technical exploration, Department of Business, Innovation and Skills Research Paper 113, https://www.gov.uk/government/uploads/system/uploads/attachment_data/file/237411/b is-13-918-efficiency-in-higher-education-sector.pdf 
Johnes, J. (2006) Data envelopment analysis and its application to the measurement of efficiency in higher education, Economics of Education Review, 25, 273-288.

Johnes, J. (2008) Efficiency and production change in the English higher education sector from 1996/7 to 2004/5, Manchester School, 76, 653-674.

Joumady, O. and C. Ris (2005) Performance in European higher education: a non-parametric production frontier approach, Education Economics, 13, 189-205.

Pastor, J.T., J.L. Ruiz and I. Sirvent (1999) An enhanced DEA Russell graph efficiency measure, European Journal of Operational Research, 115, 596-607.

Simar, L. and P.W. Wilson (1998) Sensitivity analysis of efficiency scores: how to bootstrap in nonparametric frontier models, Management Science, 44, 49-61.

Smith, P.C. and A. Street (2006) Analysis of secondary school efficiency: final report, Department for Education and Skills, available at http://webarchive.nationalarchives.gov.uk/20130401151715/http://www.education.gov.uk /publications/eOrderingDownload/RR788.pdf.

Thanassoulis, E., M. Kortelainen, G. Johnes and J. Johnes (2011) Costs and efficiency of higher education institutions in England: a DEA analysis, Journal of the Operational Research Society, 62, 1282-1297.

Tone, K. (2001) A slacks based measure of efficiency in data envelopment analysis, European Journal of Operational Research, 130, 498-509.

Tone, K. (2015) Slacks based measure variations revisited, INFORMS Conference, Philadelphia, 3 November, https://grips.repo.nii.ac.jp/?action=repository_uri\&item_id=1176\&file_id=20\&file_no=1.

Wolszczak-Derlacz, J. and A. Parteka (2011) Efficiency of European public higher education institutions: a two-stage multicountry approach, Scientometrics, 89, 887-917. 
Table 1 Descriptive statistics

\begin{tabular}{lcccc}
\hline method & minimum & lower quartile & median & upper quartile \\
\hline SBM-Min & 0.0051 & 0.1629 & 0.3237 & 0.6605 \\
CCR & 0.0881 & 0.6634 & 0.7539 & 0.8110 \\
SBM-Max & 0.0543 & 0.7230 & 0.8290 & 0.8813 \\
\hline
\end{tabular}

Table 2 Correlation matrices

\begin{tabular}{|c|c|c|}
\hline \multicolumn{3}{|c|}{ Full sample correlation matrix } \\
\hline & SBM-Min & CCR \\
\hline CCR & 0.576 & \\
\hline SBM-Max & 0.443 & 0.812 \\
\hline \multicolumn{3}{|c|}{ Full sample rank correlation matrix } \\
\hline & SBM-Min & CCR \\
\hline CCR & 0.536 & \\
\hline SBM-Max & 0.328 & 0.659 \\
\hline \multicolumn{3}{|c|}{ Large institutions correlation matrix } \\
\hline & SBM-Min & CCR \\
\hline CCR & 0.515 & \\
\hline SBM-Max & 0.328 & 0.811 \\
\hline \multicolumn{3}{|c|}{ Large institutions rank correlation matrix } \\
\hline & SBM-Min & CCR \\
\hline CCR & 0.482 & \\
\hline SBM-Max & 0.175 & 0.645 \\
\hline
\end{tabular}




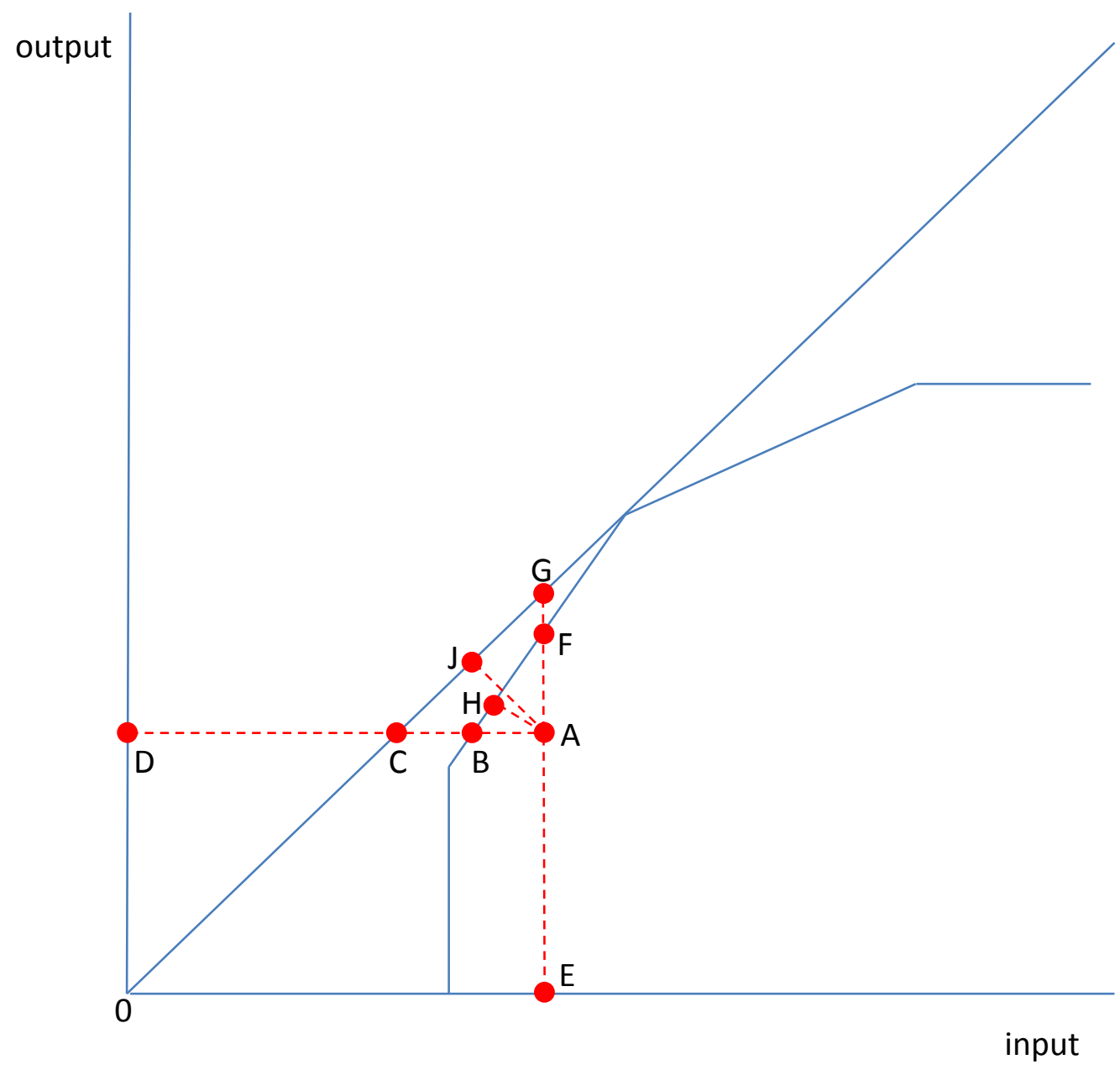

Figure 1 Comparison of frontier methods

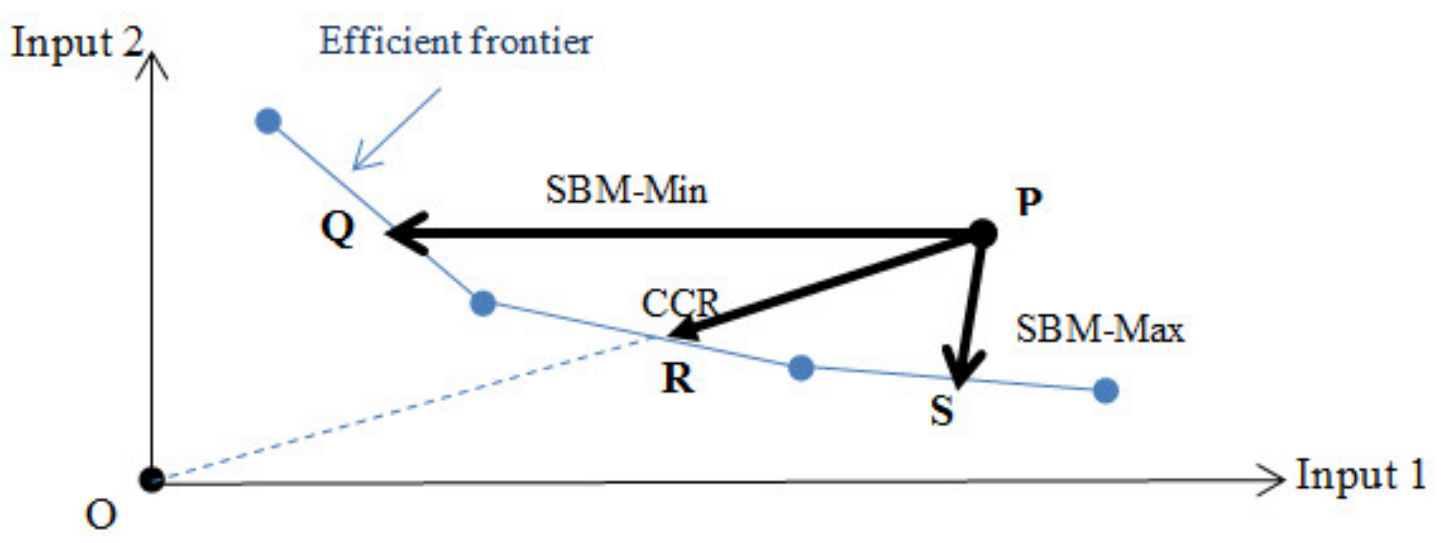

Figure 2 CCR, SBM-Min and SBM-Max compared 


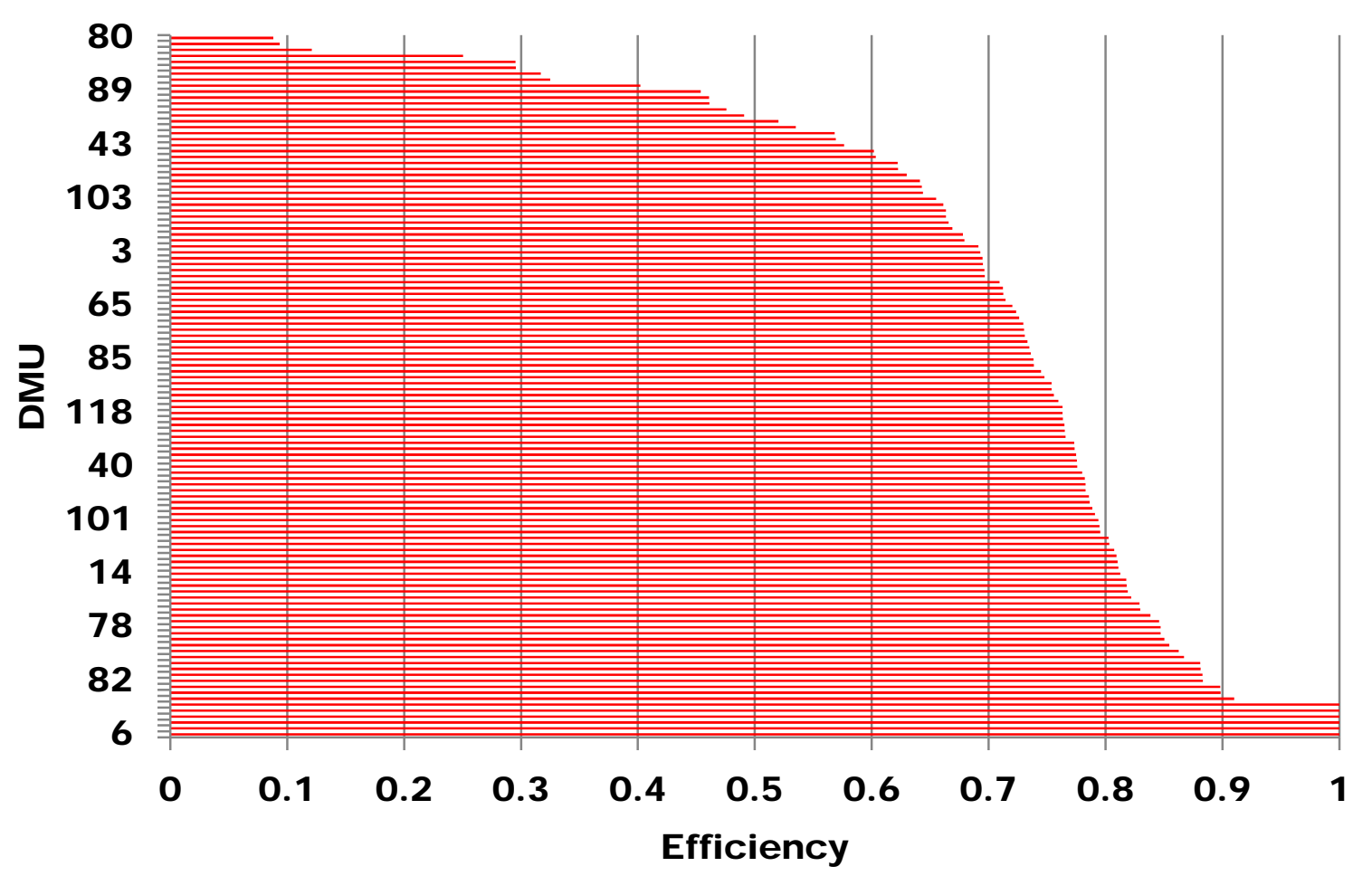

Figure 3 Distribution of efficiencies of higher education institutions, CCR model 


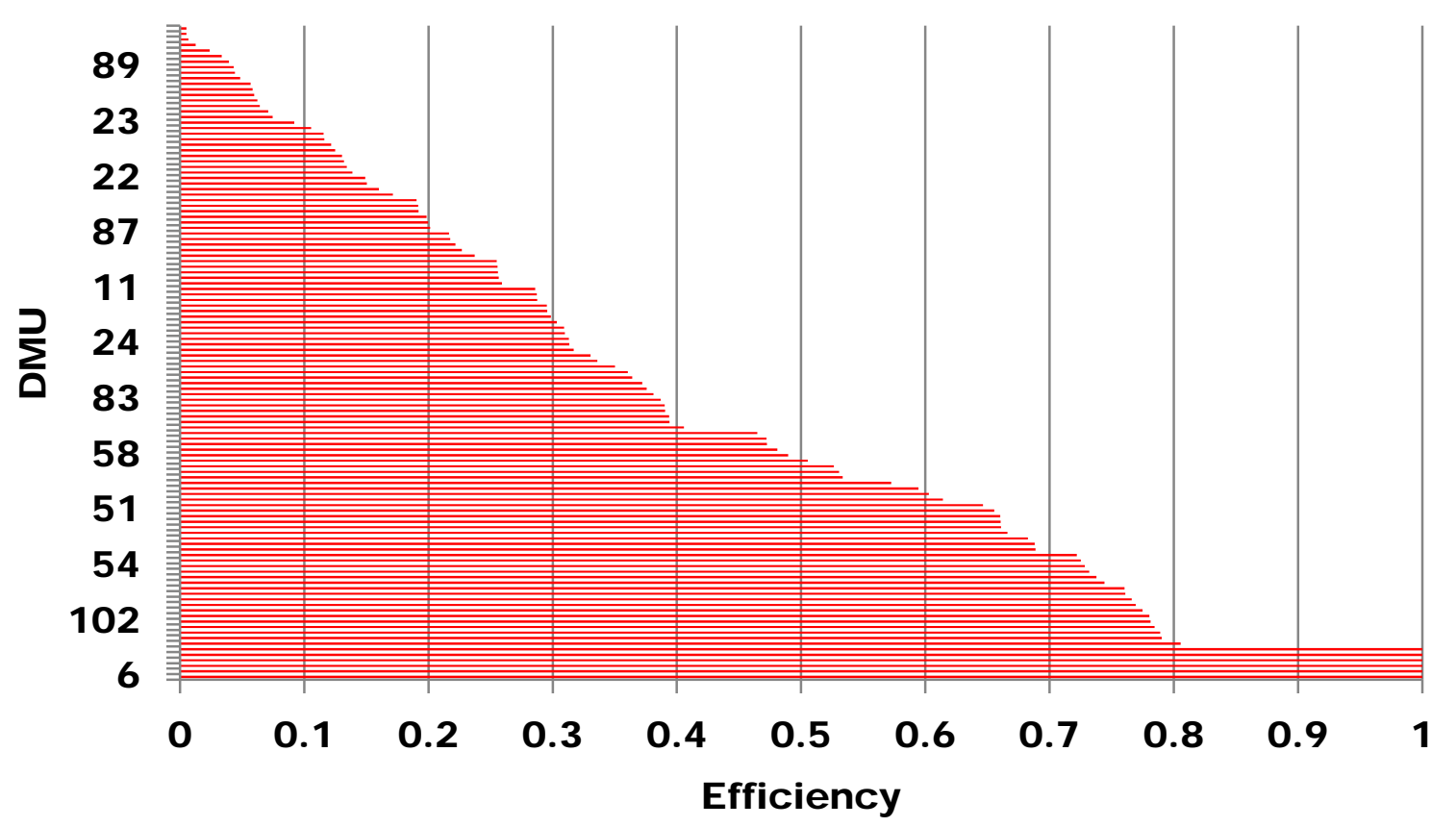

Figure 4 Distribution of efficiencies of higher education institutions, SBM-Min model 


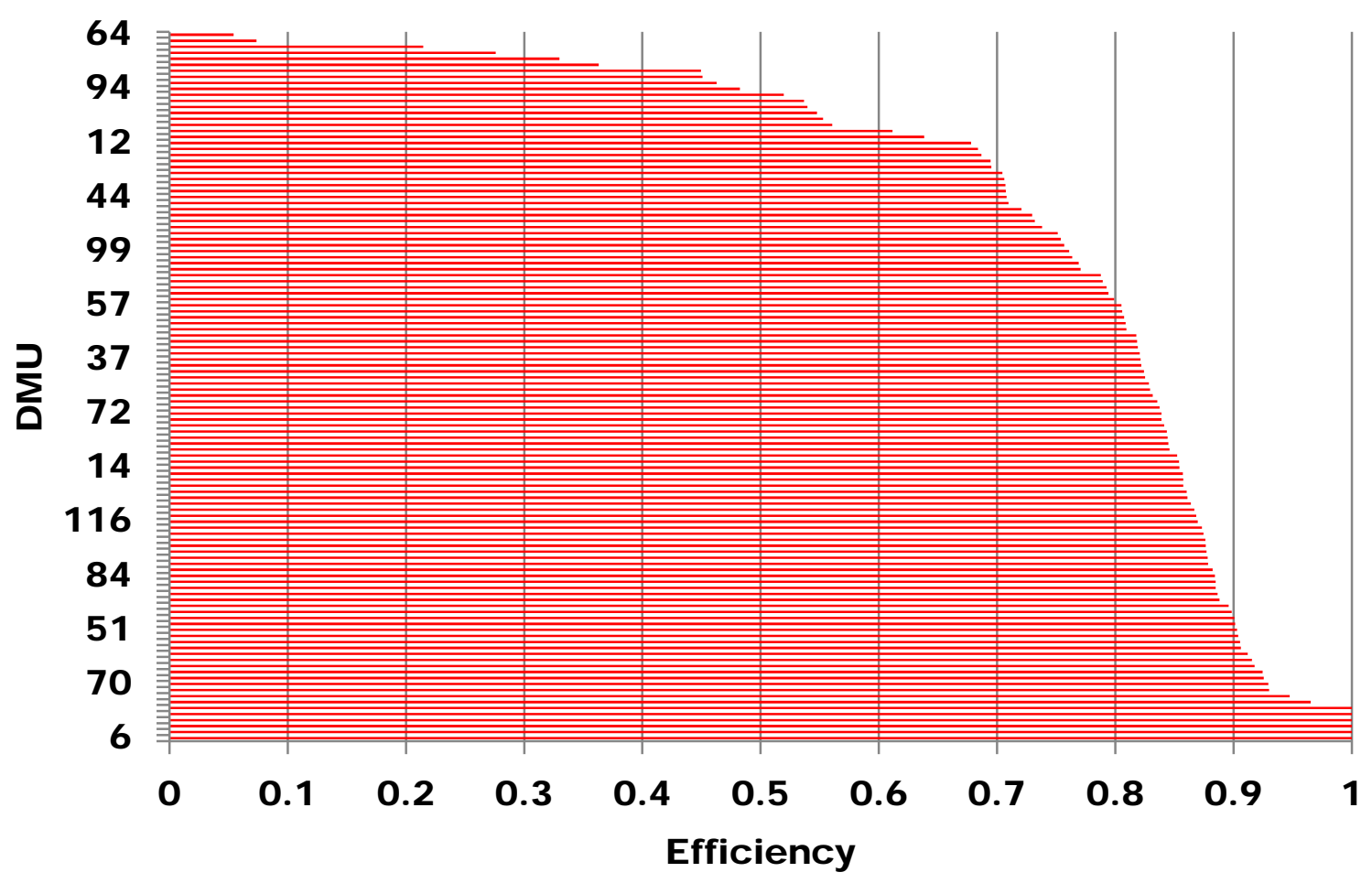

Figure 5 Distribution of efficiencies of higher education institutions, SBM-Max model 


\section{Appendix}

Table A1 Efficiency scores

\begin{tabular}{|c|c|c|c|}
\hline Higher Education Institution & SBM-Min & CCR & SBM-Max \\
\hline Anglia Ruskin University & 0.1916 & 0.6793 & 0.8444 \\
\hline Aston University & 0.4724 & 0.6658 & 0.6945 \\
\hline Bath Spa University & 0.0711 & 0.6929 & 0.8523 \\
\hline The University of Bath & 0.7605 & 0.8105 & 0.8747 \\
\hline University of Bedfordshire & 0.2957 & 0.7828 & 0.9039 \\
\hline Birkbeck College & 1.0000 & 1.0000 & 1.0000 \\
\hline Birmingham City University & 0.3168 & 0.8292 & 0.9302 \\
\hline The University of Birmingham & 0.7844 & 0.8191 & 0.8219 \\
\hline Bishop Grosseteste University & 1.0000 & 1.0000 & 1.0000 \\
\hline The University of Bolton & 0.3757 & 0.7749 & 0.9013 \\
\hline Bournemouth University & 0.2858 & 0.7123 & 0.8573 \\
\hline The University of Bradford & 0.4055 & 0.6411 & 0.6781 \\
\hline The University of Brighton & 0.4809 & 0.7632 & 0.7319 \\
\hline The University of Bristol & 0.7376 & 0.8125 & 0.8542 \\
\hline Brunel University London & 0.6603 & 0.7304 & 0.7635 \\
\hline Buckinghamshire New University & 0.2216 & 0.7955 & 0.8882 \\
\hline The University of Cambridge & 0.2567 & 0.6020 & 0.6869 \\
\hline The Institute of Cancer Research & 0.0598 & 0.8505 & 0.2759 \\
\hline Canterbury Christ Church University & 0.2559 & 0.8626 & 0.9120 \\
\hline The University of Central Lancashire & 0.3605 & 0.7596 & 0.8849 \\
\hline Central School of Speech and Drama & 0.1304 & 0.4758 & 0.6840 \\
\hline University of Chester & 0.1492 & 0.7650 & 0.8772 \\
\hline The University of Chichester & 0.0919 & 0.7800 & 0.9056 \\
\hline The City University & 0.3133 & 0.5352 & 0.7097 \\
\hline Courtauld Institute of Art & 0.3811 & 0.6034 & 0.5605 \\
\hline Coventry University & 0.2984 & 0.7234 & 0.7925 \\
\hline Cranfield University & 0.3902 & 0.7361 & 0.7569 \\
\hline University for the Creative Arts & 0.0336 & 0.5692 & 0.7062 \\
\hline University of Cumbria & 0.1055 & 0.7829 & 0.8822 \\
\hline De Montfort University & 0.3721 & 0.7539 & 0.8866 \\
\hline University of Derby & 0.0569 & 0.6301 & 0.8242 \\
\hline University of Durham & 0.7749 & 0.7857 & 0.8074 \\
\hline The University of East Anglia & 0.7251 & 0.7755 & 0.8252 \\
\hline The University of East London & 0.1601 & 0.6226 & 0.8179 \\
\hline Edge Hill University & 0.0744 & 0.8547 & 0.7691 \\
\hline The University of Essex & 0.7903 & 0.8472 & 0.8296 \\
\hline The University of Exeter & 0.7803 & 0.7949 & 0.8212 \\
\hline Falmouth University & 0.1216 & 0.6223 & 0.8183 \\
\hline University of Gloucestershire & 0.2373 & 0.7824 & 0.8685 \\
\hline Goldsmiths College & 0.5725 & 0.7758 & 0.8764 \\
\hline The University of Greenwich & 0.4723 & 0.7296 & 0.7208 \\
\hline Guildhall School of Music and Drama & 0.0484 & 0.2505 & 0.4629 \\
\hline
\end{tabular}




\begin{tabular}{|c|c|c|c|}
\hline Harper Adams University & 0.3361 & 0.5765 & 0.7045 \\
\hline University of Hertfordshire & 0.3906 & 0.6782 & 0.7080 \\
\hline Heythrop College & 0.1320 & 0.5684 & 0.7075 \\
\hline The University of Huddersfield & 1.0000 & 1.0000 & 1.0000 \\
\hline The University of Hull & 0.5305 & 0.7657 & 0.8732 \\
\hline Imperial College of Science, Technology and Medicine & 1.0000 & 1.0000 & 1.0000 \\
\hline Institute of Education & 1.0000 & 1.0000 & 1.0000 \\
\hline The University of Keele & 0.6030 & 0.7145 & 0.6953 \\
\hline The University of Kent & 0.6553 & 0.8386 & 0.9030 \\
\hline King's College London & 0.6887 & 0.7910 & 0.8057 \\
\hline Kingston University & 0.2013 & 0.6950 & 0.8576 \\
\hline The University of Lancaster & 0.7284 & 0.8181 & 0.8640 \\
\hline Leeds Beckett University & 0.2873 & 0.8671 & 0.9474 \\
\hline The University of Leeds & 0.7662 & 0.8025 & 0.8450 \\
\hline Leeds Trinity University & 0.7220 & 0.7478 & 0.8051 \\
\hline The University of Leicester & 0.4895 & 0.8221 & 0.9180 \\
\hline The University of Lincoln & 0.1504 & 0.7865 & 0.9009 \\
\hline Liverpool Hope University & 0.5053 & 0.8111 & 0.9156 \\
\hline Liverpool John Moores University & 0.6464 & 0.7092 & 0.7894 \\
\hline The University of Liverpool & 0.0442 & 0.5201 & 0.7540 \\
\hline University of the Arts, London & 0.0623 & 0.1209 & 0.2145 \\
\hline London Business School & 0.0126 & 0.0937 & 0.0543 \\
\hline London Metropolitan University & 0.1388 & 0.7202 & 0.8762 \\
\hline London South Bank University & 0.1920 & 0.6912 & 0.8571 \\
\hline London School of Economics and Political Science & 0.4648 & 0.4907 & 0.5367 \\
\hline London School of Hygiene and Tropical Medicine & 1.0000 & 1.0000 & 1.0000 \\
\hline Loughborough University & 0.7609 & 0.7735 & 0.8206 \\
\hline The Manchester Metropolitan University & 0.3093 & 0.8296 & 0.9294 \\
\hline The University of Manchester & 0.6880 & 0.7637 & 0.7943 \\
\hline Middlesex University & 0.2268 & 0.6691 & 0.8391 \\
\hline University of Newcastle-upon-Tyne & 0.7693 & 0.8032 & 0.8374 \\
\hline Newman University & 0.1344 & 0.8812 & 0.5530 \\
\hline The University of Northampton & 0.1997 & 0.7653 & 0.8986 \\
\hline University of Northumbria at Newcastle & 0.2555 & 0.7349 & 0.8782 \\
\hline Norwich University of the Arts & 0.1986 & 0.8986 & 0.6116 \\
\hline University of Nottingham ${ }^{+}$ & 0.8054 & 0.8472 & 0.8391 \\
\hline The Nottingham Trent University & 0.3097 & 0.7887 & 0.9063 \\
\hline Oxford Brookes University & 0.0051 & 0.0881 & 0.0736 \\
\hline The University of Oxford & 0.2952 & 0.6612 & 0.8316 \\
\hline University of Plymouth & 0.5335 & 0.8834 & 0.9257 \\
\hline The University of Portsmouth & 0.3870 & 0.6634 & 0.8189 \\
\hline Queen Mary University of London & 0.3938 & 0.7538 & 0.8842 \\
\hline The University of Reading & 0.6827 & 0.7384 & 0.8087 \\
\hline Roehampton University & 0.5944 & 0.6438 & 0.7297 \\
\hline Rose Bruford College & 0.2164 & 0.8095 & 0.8539 \\
\hline Royal Academy of Music & 0.0067 & 0.2956 & 0.3629 \\
\hline
\end{tabular}




\begin{tabular}{llll}
\hline Royal Agricultural University & 0.0432 & 0.4536 & 0.4497 \\
Royal College of Art & 0.2592 & 0.4608 & 0.4509 \\
Royal College of Music & 0.0583 & 0.3169 & 0.5197 \\
Royal Holloway and Bedford New College & 0.6606 & 0.7386 & 0.8093 \\
Royal Northern College of Music & 0.0240 & 0.3249 & 0.5396 \\
The Royal Veterinary College & 0.3306 & 0.4022 & 0.4825 \\
St George's Hospital Medical School & 0.3033 & 0.4612 & 0.5477 \\
St Mary's University, Twickenham & 0.0393 & 0.8074 & 0.7072 \\
The University of Salford & 0.3129 & 0.6949 & 0.8436 \\
The School of Oriental and African Studies & 0.5264 & 0.8980 & 0.6383 \\
Sheffield Hallam University & 0.3500 & 0.7450 & 0.7609 \\
The University of Sheffield & 0.7890 & 0.8458 & 0.8414 \\
Southampton Solent University & 0.0642 & 0.7938 & 0.7708 \\
The University of Southampton & 0.7812 & 0.8829 & 0.8667 \\
Staffordshire University & 0.1248 & 0.6551 & 0.8355 \\
The University of Sunderland & 0.1163 & 0.6428 & 0.8285 \\
The University of Surrey & 0.6662 & 0.7331 & 0.7991 \\
The University of Sussex & 0.7320 & 0.7733 & 0.8457 \\
Teesside University & 0.2551 & 0.6969 & 0.8610 \\
Trinity Laban Conservatoire of Music and Dance & 0.0053 & 0.2952 & 0.3297 \\
University College London & 0.6609 & 0.8814 & 0.8850 \\
The University of Warwick & 0.6141 & 0.6635 & 0.7381 \\
University of the West of England, Bristol & 0.3640 & 0.7261 & 0.7513 \\
The University of West London & 0.1714 & 0.7558 & 0.8960 \\
The University of Westminster & 0.2877 & 0.7310 & 0.8786 \\
The University of Winchester & 0.3942 & 0.9100 & 0.9652 \\
The University of Wolverhampton & 0.2176 & 0.6964 & 0.8605 \\
University of Worcester & 0.1904 & 0.7126 & 0.8696 \\
York St John University & 0.1155 & 0.8179 & 0.9246 \\
The University of York & 0.7441 & 0.7633 & 0.7877 \\
\hline & & & \\
\hline
\end{tabular}

